Journal of Accident and Emergency Medicine 1994 11, 3-7

\title{
Changes in plasma calcium during septic shock
}

\author{
A.D. CUMMING
}

University Department of Medicine, Royal Infirmary, Lauriston Place, Edinburgh

\section{SUMMARY}

Previous studies have documented a decrease in plasma calcium occurring early after trauma, haemorrhage and cardiac arrest. Therefore, changes in plasma calcium in an ovine experimental model of septic shock due to intraperitoneal sepsis were investigated. Subjects were volume-loaded with Ringer's lactate solution. Plasma calcium and albumin were measured before and $24 \mathrm{~h}$ after surgical induction of sepsis. Subjects were divided into two groups according to the severity of shock. Group $1(n=8)$ developed severe hyperdynamic sepsis with renal failure. Group $2(n=8)$ showed no change in blood pressure, cardiac output or renal function.

Plasma calcium fell significantly in both groups, and was lower in Group 1 during sepsis (Group 1: $2.36 \pm 0.19$ to $1.84 \pm 0.14 \mathrm{mmoll}^{-1}$; Group 2: $2.34 \pm 0.12$ to $2.01 \pm 0.13 \mathrm{mmoll}^{-1}$; mean $\pm S D$; both $P<0.001$ ). Plasma albumin fell during sepsis, and the reduction was greater in Group 1. The plasma calcium, corrected for albumin, was still significantly reduced and was similar in each group during sepsis (Group 1: $2.55 \pm 0.13$ to $2.23 \pm 0.12 \mathrm{mmoll}^{-1}$; Group 2: $2.50 \pm 0.08$ to $2.27 \pm 0.09 \mathrm{mmoll}^{-1}$; both $P<0.001)$.

In this large animal model of septic shock, which reproduces the important features of clinical sepsis, there were significant decrements in uncorrected and corrected plasma calcium $24 \mathrm{~h}$ after the surgical induction of intraperitoneal sepsis. These changes may contribute to the pathophysiology of this condition.

Key words: albumin, calcium, septic shock

Correspondence: A.D. Cumming, University Department of Medicine, Royal Infirmary, Edinburgh, United Kingdom, EH3 9YW

\section{INTRODUCTION}

A decrease in plasma calcium, both total and ionized, has been observed after trauma, haemorrhage and cardiac arrest. ${ }^{1-3}$ This has been described both in experimental animals and in patients, but the pathophysiology and significance of these changes remains unclear. ${ }^{4}$ There is little information regarding plasma calcium changes in septic shock. It has been shown that the normal pressor response to intravenous calcium infusion is lost during experimental endotoxaemia; 5 however, acute changes in plasma calcium have not been documented in this condition.

Therefore changes in plasma calcium and albumin in an ovine model of septic shock as a result of intraperitoneal sepsis were investigated. This extensively studied experimental model closely resembles the haemodynamic and metabolic features of clinical sepsis. ${ }^{6,7}$ Measurements were made before and $24 \mathrm{~h}$ after surgical induction of sepsis. Animals were classified according to the severity of shock.

\section{MATERIALS AND METHODS}

This study conforms to the regulations of the Canadian Council on Animal Care and was approved by the Ethics Committee of the University of Western Ontario. The technique of surgical induction of peritonitis was modified from that of Wichterman et al. ${ }^{8}$ as described previously. ${ }^{9}$ In brief, 16 healthy sheep aged between 12 and 18 months and weighing between 45 and $50 \mathrm{~kg}$ underwent cannulation of the common carotid artery, and the pulmonary artery via the external jugular vein with a triple-lumen Swan Ganz catheter, under general anaesthesia. The bladder was catheterized per urethra. After recovery from anaesthesia, animals were volumeloaded with 31 of Ringer-lactate solution intravenously (i.v.) over $24 \mathrm{~h}$. After control haemodynamic measurements and blood and urine sampling, animals underwent a second general anaesthetic; peritonitis was induced by caecal ligation and puncture. Post-operatively all animals received $50 \mathrm{mg}$ pethidine i.v., and were continued thereafter on an i.v. infusion of pethidine $\left(50 \mathrm{mg} 6 \mathrm{~h}^{-1}\right)$. Infusion (i.v.) of Ringer-lactate solution, $125 \mathrm{ml} \mathrm{h}^{-1}$, continued for the duration of the experiment and the rate of additional fluid administration was adjusted to 
maintain pulmonary artery occlusion pressure at baseline values.

Animals were supervised continuously during the study, and if they showed any evidence of discomfort or distress, despite pethidine infusion, they were killed immediately by i.v. injection of pentobarbital.

Haemodynamic parameters measured were mean arterial pressure, central venous pressure, pulmonary artery pressure, pulmonary artery occlusion pressure, and thermodilution cardiac output. Plasma creatinine, sodium, potassium, calcium, phosphate and albumin were measured by standard techniques. Plasma calcium was corrected for plasma albumin using the formula:

adjusted plasma $\mathrm{Ca}=$ measured $\mathrm{Ca}+0.02 \times$

(40 - plasma albumin)

For analysis, for each variable, the values included were those at baseline (pre-sepsis), and at the termination of the study ( $24 \mathrm{~h}$ post-operatively). As appropriate, paired or unpaired Student's $t$-tests, corrected for multiple comparisons, were used to assess the significance of changes with time, and the significance of between-group differences. Values for $P<0.05$ were taken to be significant. All results are shown as Mean \pm SD.

\section{RESULTS}

As in the studies performed to establish and validate this experimental model, ${ }^{6,7,9}$ a polymicrobial peritonitis and bacteraemia developed; organisms grown on blood culture included E.coli, Serratia, Enterobacter, Pseudomonas and Bacteroides species.

Pulmonary artery occlusion pressure was main- tained in the range $10-20 \mathrm{mmHg}$ during the study (mean $13.7 \pm 2.2 \mathrm{mmHg}$ ). In Group 1 (severe sepsis, $n=8$ ), there was a small but significant fall with time in blood pressure, a $50 \%$ reduction in systemic vascular resistance index, an increase in pulmonary artery pressure, and a reduction in creatinine clearance and fractional sodium excretion. In Group 2 (moderate sepsis, $n=8$ ), these parameters did not alter significantly (Table 1). Plasma calcium fell significantly in both groups, and was lower in Group 1 during sepsis (Group 1: $2.36 \pm 0.19$ to $1.84 \pm 0.14 \mathrm{mmoll}^{-1}, P<0.001$; Group 2: $2.34 \pm$ 0.12 to $2.01 \pm 0.13 \mathrm{mmoll}^{-1} ; P<0.001$. Group 1 vs. Group 2 at $24 \mathrm{~h}, P<0.05$.) (Fig. 1). The fall in plasma albumin was greater in Group 1: $30.3 \pm 3.7$ to $20.8 \pm 5.0 \mathrm{gl}^{-1}, P<0.001$; Group 2: $32.1 \pm 3.9$ to $27.0 \pm 3.0 \mathrm{gl}^{-1}, P<0.001$. Group 1 vs. Group 2 at $24 \mathrm{~h}, P<0.05$ (Fig. 2).

The plasma calcium, corrected for plasma albumin, was similar in each group during sepsis, although still significantly reduced (Group $1 ; 2.55 \pm 0.13$ to $2.23 \pm 0.12 \mathrm{mmoll}^{-1}, P<0.01$. Group 2; $2.50 \pm 0.08$ to $2.27 \pm 0.09 \mathrm{mmoll}^{-1}, P<0.05$ ) (Fig. 3).

\section{DISCUSSION}

Studies of electrolyte changes in clinical septic shock are complicated by lack of pre-sepsis baseline parameters, problems in assessing the stage and severity of the shock syndrome, and the multiple treatments required. The experimental model of sepsis utilized in this study overcomes these difficulties, and reproduces the state of volume-loaded, hyperdynamic and vasodilated septic shock typically seen in clinical practice. ${ }^{6,7,9}$ As part of a detailed investigation of neuroendocrine function and the

Table 1. Haemodynamic and renal function variables in Group 1 (severe sepsis) and Group 2 (moderate sepsis), ${ }^{*} P<0.05$ vs. baseline

\begin{tabular}{|c|c|c|c|c|c|}
\hline & & \multicolumn{2}{|c|}{ Group 1} & \multicolumn{2}{|c|}{ Group 2} \\
\hline & & Baseline & $24 \mathrm{~h}$ & Baseline & $24 h$ \\
\hline $\begin{array}{l}\text { Mean arterial } \\
\text { pressure }\end{array}$ & $\mathrm{mmHg}$ & $108 \pm 5$ & $90 \pm 3^{*}$ & $96 \pm 4$ & $100 \pm 6$ \\
\hline $\begin{array}{l}\text { Systemic vascular } \\
\text { resistance }\end{array}$ & $\begin{array}{l}\text { dyne } \mathrm{s}^{-1} \\
\mathrm{~cm}^{-5} \mathrm{~m}^{-2}\end{array}$ & $2183 \pm 243$ & $1038 \pm 107^{\star}$ & $2026 \pm 244$ & $1677 \pm 179$ \\
\hline $\begin{array}{l}\text { Pulmonary artery } \\
\text { pressure }\end{array}$ & $\mathrm{mmHg}$ & $16 \pm 1.3$ & $22 \pm 1.1^{\star}$ & $18 \pm 1.8$ & $21 \pm 1$ \\
\hline $\begin{array}{l}\text { Creatinine } \\
\text { clearance }\end{array}$ & $\mathrm{ml} \min ^{-1}$ & $142 \pm 15$ & $43 \pm 8^{*}$ & $152 \pm 30$ & $123 \pm 14$ \\
\hline $\begin{array}{l}\text { Fractional sodium } \\
\text { excretion }\end{array}$ & $\%$ & $2.9 \pm 0.5$ & $0.5 \pm 0.2^{*}$ & $2.6 \pm 0.5$ & $2.0 \pm 0.7$ \\
\hline
\end{tabular}


Changes in plasma calcium during septic shock
Fig. 1. Plasma calcium before and $24 \mathrm{~h}$ after surgical induction of sepsis in Group 1 (severe sepsis) and Group 2 (moderate sepsis).

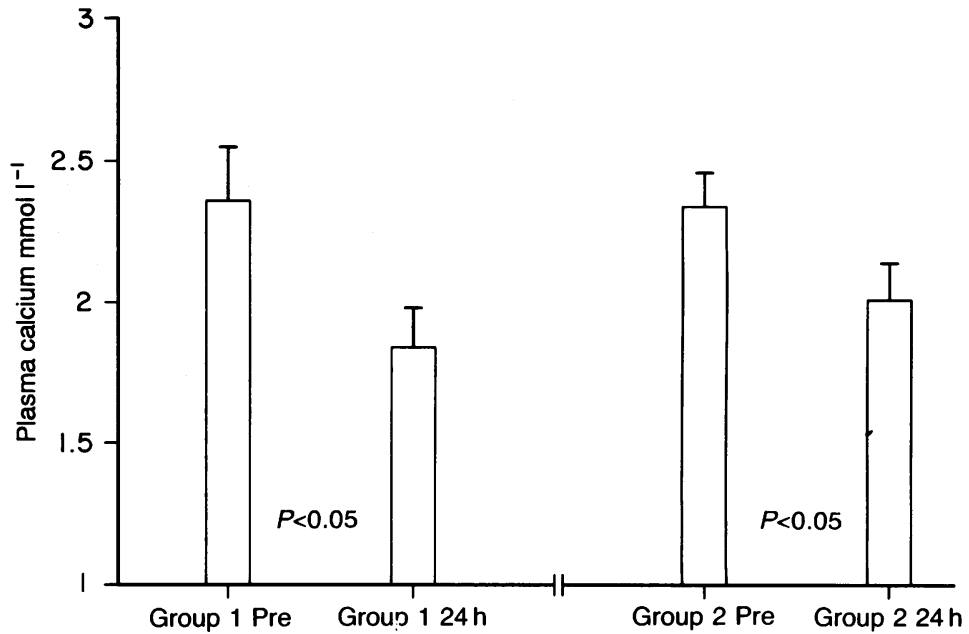

Fig. 2. Plasma albumin before and $24 \mathrm{~h}$ after surgical induction of sepsis in Group 1 (severe sepsis) and Group 2 (moderate sepsis).

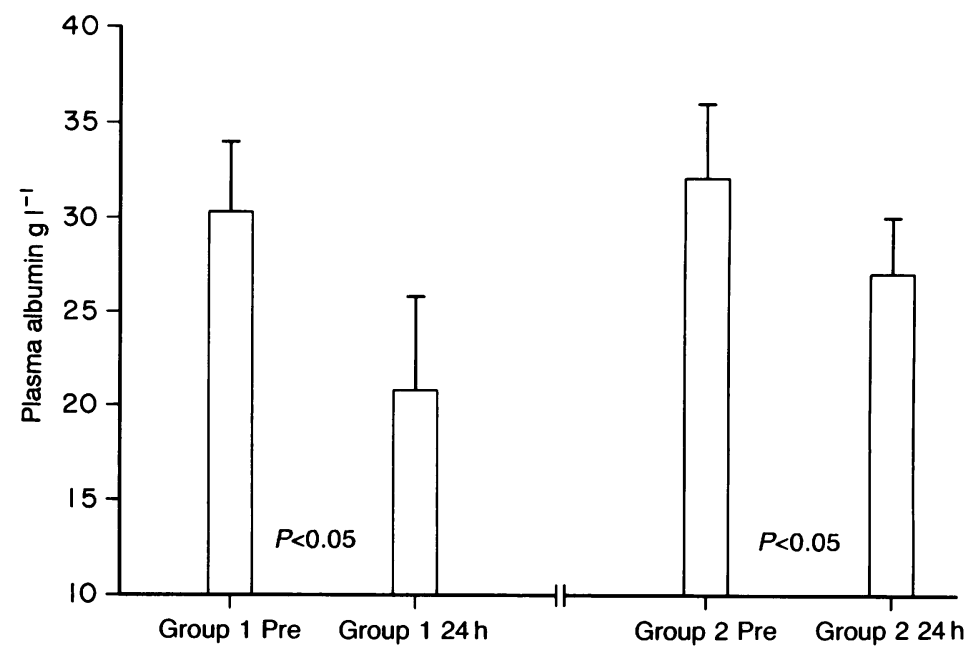

Fig. 3. Plasma calcium, adjusted for plasma albumin, before and $24 \mathrm{~h}$ after surgical induction of sepsis in Group 1 (severe sepsis) and Group 2 (moderate sepsis).

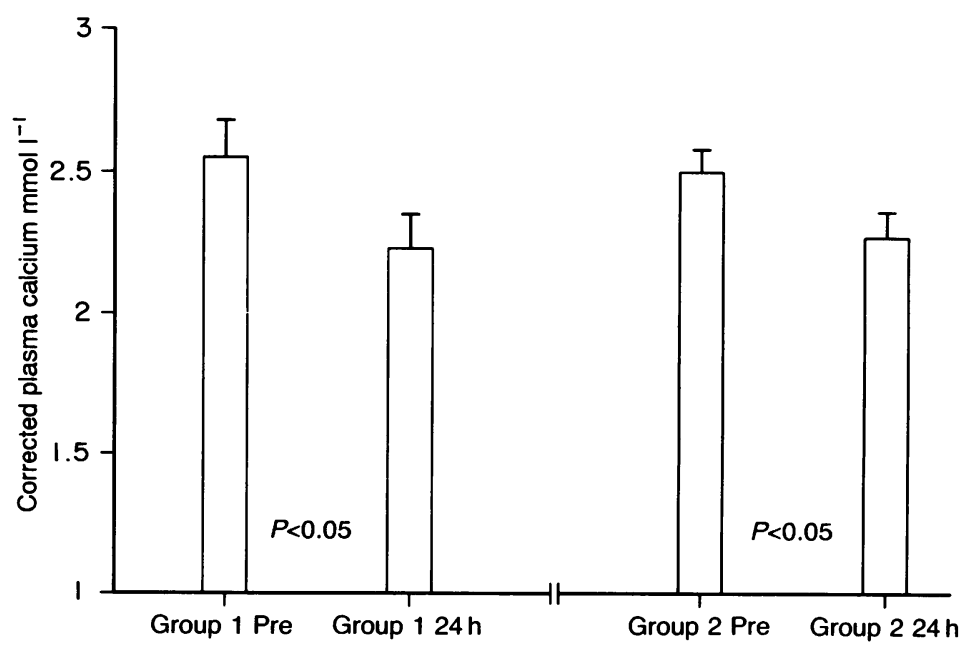

pathogenesis of acute renal failure in sepsis, plasma calcium and albumin were measured, and significant changes observed.

In these studies, plasma calcium was reduced

$24 \mathrm{~h}$ after surgical induction of sepsis. While this fall was less marked when adjusted for the plasma calcium, it was still significant. It should be noted that this occurred despite the administration of large volumes of Ringer-lactate solution $\left(125 \mathrm{mlh}^{-1}\right)$. This solution contains $2 \mathrm{mmoll}^{-1}$ of calcium as 
A.D. Cumming calcium chloride, which is entirely ionized. It seems likely that even greater reductions in plasma calcium would have been seen if non-calcium containing fluids had been used for volume replacement.

It is known that the plasma total calcium concentration falls acutely in patients suffering from major trauma and/or haemorrhagic shock. ${ }^{1,2}$ This is not dependent on citrate infused during transfusion. ${ }^{10}$ There is an equivalent, or even greater, fall in ionized calcium, and infusion of colloids such as albumin may disguise this decrease, by a disproportionate effect on total calcium concentration. ${ }^{10}$ Similar data are available for patients who are resuscitated from cardiorespiratory arrest. ${ }^{3,4}$ In haemorrhagic shock, the hypocalcaemia may persist after resuscitation for up to 6 days, in the absence of supplementation. ${ }^{10}$ It has been suggested that in these patients, hypocalcaemia may be associated with depression of myocardial performance and vascular contractility. ${ }^{11}$ Beneficial effects of calcium supplementation on cardiocirculatory function have been described in patients with traumatic, haemorrhagic and cardiogenic shock. ${ }^{1,2,10-12}$

McCaig \& Parratt ${ }^{5}$ have shown that in cats infused with endotoxin, there is markedly reduced myocardial and vascular responsiveness to infusions of calcium chloride. Before infusion of endotoxin, calcium infusion produced a pressor response of $24 \mathrm{mmHg}$; however, no pressor effect was seen after endotoxin. This was ascribed to damage to receptor-operated calcium channels. ${ }^{13}$ It seems likely that this phenomenon may aggravate the adverse haemodynamic consequences of a fall in plasma calcium during sepsis.

Increased uptake of calcium by skeletal muscle during sepsis has been demonstrated in rats using the caecal ligation and puncture model. ${ }^{14}$ However, it was not clear whether this was accompanied by, or responsible for, any change in plasma calcium. It should be recalled that the extracellular calcium concentration is normally of the order of 16000 times higher than the intracellular concentration. ${ }^{15}$ Although it has been suggested that this calcium influx may act as a trigger to catabolism of skeletal muscle in sepsis, this has not been proved conclusively. ${ }^{14}$ However, it may well be involved in the increased glucose uptake by skeletal muscle seen in sepsis, which in turn may contribute to hypoglycaemia and increased lactate production. ${ }^{16}$

In septic shock, the combination of a reduced plasma calcium, and decreased myocardial and vascular sensitivity to calcium, would be predicted to contribute to circulatory compromise, which could be at least partly reversible by calcium infusion. Many emergency units and intensive therapy units now have the capacity to measure plasma ionized calcium. The authors' clinical experience using such a procedure suggests that in critically ill patients, including those with septic shock, the incidence of hypocalcaemia, and the benefits of calcium supplementation, have been underestimated.

\section{ACKNOWLEDGEMENTS}

The author would like to thank the Kidney Foundation of Canada for financial support.

\section{REFERENCES}

1. Trunkey D., Holcroft J. \& Carpenter M.A. (1976) Calcium flux during haemorrhage shock in baboons. The Journal of Trauma 16, 633-638.

2. Harrigan C., Lucas C.E. \& Ledgerwood A.M. (1983) Significance of hypocalcaemia following hypovolaemic shock. The Journal of Trauma 23, 488-493.

3. Gando S., Tedo I. \& Kubota M. (1990) A comparison of serum ionised calcium in arterial and mixed venous blood during CPR. Annals of Emergency Medicine 19, 850-856.

4. Erdmann E. \& Reuschel-Janetschek E. (1991) Calcium for resuscitation? British Journal of Anaesthesia 67, 178-184.

5. McCaig D.J. \& Parratt J.R. (1980) Reduced myocardial response to calcium during endotoxin shock in the cat. Circulatory Shock 7, 189-201.

6. Cumming A.D., Kline R. \& Linton A.L. (1988) Association between renal and sympathetic responses to non-hypotensive systemic sepsis. Critical Care Medicine 16, 1132.

7. Cumming A.D. \& Nimmo G.R. (1992) Hemodynamic, renal and hormonal actions of aprotinin in an ovine model of septic shock. Critical Care Medicine 20, 1134-1139.

8. Wichterman K.A., Baur A.E. \& Chaudry I.H. (1980) Sepsis and septic shock - a review of laboratory models and a proposal. Journal of Surgical Research 29, 189.

9. Cumming A.D., Dreidger A.A., McDonald J.W., Lindsay R.M., Solez K. \& Linton A.L. (1988) Vasoactive hormones in the renal response to systemic sepsis. American Journal of Kidney Diseases 11, 23-32.

10. Kovalik S.G., Ledgerwood A.M., Lucas C.E., Higgins R.F. (1981) The cardiac effect of altered calcium homeostasis after albumin resuscitation. The Journal of Trauma 21, 275-279.

11. Denis R., Lucas C.E., Ledgerwood A.M., Wallace J.R., Grabow D.E., Harrigan C. \& Dawe E.J. (1988) The beneficial role of calcium supplementation during 
Changes in plasma calcium during septic shock resuscitation from shock. The Journal of Trauma 25 , 594-600.

12. Zaloga G., Prielipp R., Dudas L., Royster R. \& Butterworth J. (1991) Calcium (Ca) impairs dobutamine's cardiovascular actions. Critical Care Medicine 19, S52.

13. Parratt J.R. (1989) Alterations in vascular reactivity in sepsis and endotoxaemia. In: Update in Intensive Care and Emergency Medicine, (ed. Vincent J.L.), pp. 299-308. Springer-Verlag, Berlin.

14. Benson D.W., Hasselgren P.-O., Hiyama D.T., James J.H., Li S., Rigel D.F. \& Fischer J.E. (1989) Effect of sepsis on calcium uptake and content in skeletal muscle and regulation in vitro by calcium of total and myofibrillar protein breakdown in control and septic muscle: results from a preliminary study. Surgery 106, 87-93.

15. Van Breemen C. \& Saida K. (1989) Cellular mechanisms regulating $\left[\mathrm{Ca}^{2+}\right]_{i}$ in smooth muscle. Annual Review of Physiology 51, 315-329.

16. Westfall M.V. \& Sayeed M.M. (1989) Effect of diltiazem on skeletal muscle 3-O-methylglucose transport in bacteremic rats. American Journal of Physiology 256, R716-R721. 